\title{
Una lectura filosófica a La ceniza del libertador de Fernando Cruz Kronfly
}

\author{
A philosophical reading La ceniza del libertador by \\ Fernando Cruz Kronfly
}

Edwin Alonso Vargas Bonilla

"Una gran novela es la representación simbólica de la condición humana."

José Saramago

\begin{abstract}
Resumen
La Ceniza del libertador (1987) de Fernando Cruz Kronfly reinventa los últimos días de Simón Bolívar en su viaje desde Honda hasta Santa Marta a través del río Magdalena. Digo aquí reinventa y no cuenta, dado que el autor se interesa más en reflexionar sobre los universales propios de la existencia a través de Bolívar, que en narrar al pie de la letra los hechos históricos. De esta manera puede observarse cómo la literatura presenta oportunidades de pensar cuestiones fundamentales de la vida por medio de la ficción, construida a partir del lenguaje poético. Fundado en este presupuesto, el siguiente ensayo busca realizar una lectura filosófica de la novela teniendo en cuenta las claves que el mismo autor señala en La sombrilla planetaria (1994), para luego evidenciar cómo se ponen en escena las ideas filosóficas por medio de imágenes poéticas, lo cual permite profundizar en tópicos como la estética de la muerte, el tiempo y la condición humana.

Palabras Clave: Novela histórica; reflexión filosófica; lenguaje poético; La Ceniza del libertador; Fernando Cruz Kronfly; La sombrilla planetaria.
\end{abstract}

\begin{abstract}
La Ceniza del Libertador (1987) by Fernando Cruz Kronfly reinvents the last days of Simón Bolívar in his trip from Honda to Santa Marta by the Magdalena River. I say reinvents, rather than narrates, since the author is more interested in reflecting about the universals proper of human existence through Bolívar, than in meticulously narrating historical data. In this way, it is possible to observe how literature presents opportunities to think about fundamental questions of life by means of fiction built from poetic language. Based on this idea, the following essay intends to carry out a philosophical reading of the novel taking into account the hints that the same author highlights in La sombrilla planetaria (1994) to later evince how philosophical ideas are portrayed by means of poetic images, which permits to analyze in depth, topics such as aesthetics in death, time and human condition.
\end{abstract}

Keywords: Historical novel; philosophical reflection; poetic language; La Ceniza del libertador; Fernando Cruz Kronfly; La sombrilla planetaria.

\section{Claves para una lectura filosófica}

En La sombrilla planetaria (1994), Fernando Cruz Kronfly publica el ensayo titulado “Ficción y novela histórica", escrito en el otoño alemán de 1992, en el que propone su 
pensamiento alrededor de la relación historia-ficción, tomando como punto de referencia La ceniza del libertador (1987). Según el autor vallecaucano, su novela, a la manera de $L a$ muerte de Virgilio (1958) de Hermann Broch, reflexiona sobre la paradoja humana de quien, habiendo vivido en la gloria, debe descender hacia la muerte doblegado por la soledad, el abandono, la incertidumbre, la miseria y la incomprensión. Simón Bolívar, "harapo en desuso al final de su vida" (Cruz Kronfly, 1994: 185), encarna tal paradoja, por lo que, a pesar de representar un personaje histórico reconocido, no se tomará como fin del relato sino como medio para una reflexión filosófica sobre la condición humana. En tal sentido, la intención del novelista consiste en: "Escribir una novela, por tanto, no exactamente sobre Bolívar sino sobre la paradoja por él vivida respecto del poder y la gloria, de una parte, y la miseria y el olvido, de la otra" (Cruz Kronfly, 1994: 186). Siguiendo con lo anterior, la idea original de la novela no es otra que tratar a Bolívar como pretexto para ilustrar la escisión interna que se produce en el ser humano, entre la relación paradójica de dos universales propios de -lo que Kundera llama- la condición humana,

En realidad se trataba de Bolívar, sí, pero fundamentalmente se trataba de bastante más que eso. La siguiente idea, vuelta imagen sintética, iluminaba el proyecto: el desgarramiento humano en torno de dos universales propios de la condición humana, la gloria-poder, de un lado, y del otro el olvido, la miseria y el abandono incomprendido. (Cruz Kronfly, 1994: 189).

De esta manera, se pone ante la mirada de los lectores a un Bolívar que funge como metáfora y símbolo de la condición paradójica del ser humano, del mismo modo como el Virgilio de Broch representa la paradoja entre el artista y el poder. Así las cosas, La ceniza del libertador no es hija de la historia patria sino de otra novela. En esta misma dirección, Cruz Kronfly afirma:

"Lo que la novela histórica hace, para independizarse positivamente de la historia y permitir al lector otro tipo de reflexión metahistórica, es apropiarse de los hechos históricos y de los personajes como medios para ir más allá, hacia la puesta en escena de los universales" (Cruz Kronfly, 1994: 192).

En este orden de ideas, se puede decir que el relato no se centra tanto en la reproducción fidedigna de los datos históricos respecto al último viaje del libertador sino, siguiendo la lógica reiterativa del autor, en poner en escena el drama final de un hombre que, habiendo alcanzado la gloria por sus méritos heroicos, empieza a recorrer un camino de espinas, 
cuesta abajo: al lago del olvido y la muerte. Para finalizar esta breve introducción, dejemos que sea el mismo Cruz Kronfly quien hable:

Mi novela no es, pues, una novela sobre Bolívar sino a través de Bolívar, rumbo al enigma de los dramas universales propios de la condición paradojal del hombre. La novela histórica, insisto, ofrece un alto riesgo: el de pertenecer a un género que fluctúa entre la verdad ya sabida por los historiadores y esa nueva verdad nacida de la ficción y la elaboración literarias, que sólo puede, a mi juicio, superar el dato histórico y situarse en el territorio de la imaginación, si recurre a la metáfora, al símbolo o a cualquier otro instrumento literario en función de explorar los denominados dramas universales del hombre. En mi texto, la relación paradojal entre gloria y miseria, poder y olvido (Cruz Kronfly, 1994: 193-194).

\section{Puesta en escena de las ideas filosóficas}

La primera línea puede leerse con cierto aire de sentencia: "Su excelencia ha decidido partir para siempre" (Cruz Kronfly, 1987: 9). Sin embargo esta frase, más que una sentencia, señala tres aspectos que prevalecen en toda la novela: Su Excelencia: indica el tono de respeto con el que el narrador se referirá al Bolívar-personaje, dada su posición de dignidad en el imaginario colectivo histórico. Ha decidido: este Bolívar-personaje ha tomado una decisión. Pero, ¿en qué consiste dicha disposición? ¿Cuál es el motivo de su determinación? Alrededor de estas cuestiones se profundizará a través del relato.

Partir para siempre: en esto consiste su decisión: ir hacia la muerte, al olvido, en medio de la miseria de su condición humana. Es así como la presencia de la muerte empieza a hacer carrera desde la primera página, trenzada con la atmósfera construida: "Tendida, la tierra predica su viejo sermón de perro echado, muerde ella misma el polvo húmedo en medio de vientos que lo cubren todo de un cierto color de daguerrotipo" (Cruz Kronfly, 1987: 9), lo cual señala también, de entrada, la oscuridad misma de la miseria humana. Y una voz quejumbrosa se deja escuchar: “¿Qué hago con estas tripas, José, qué hago?-murmura”, idea fija que sugiere el hastío de la existencia que pesa en la interioridad.

Al considerar las botas embarradas del general, nos ponemos ante "una extraña metafísica de hechos cumplidos", de los que no puede sino pensarse que ya todo acabó, que sólo queda el lodo de la desventura, el fango del fracaso. Sobrevive un "fino espolvoreo del prestigio, del honor”, que poco a poco se irá difuminando, con el cual Bolívar "avanza hacia las aguas" (Cruz Kronfly, 1987: 10). 
No el agua en singular: las aguas, en plural; es decir, el río, que lo llevará al mar. Río que se convierte en camino a la inmensidad del mar de la muerte. A medida que el viaje transcurre, "atrás van quedando" los últimos vestigios de gloria y poder. Un viaje sin retorno al último límite, en el que se dirige la mirada hacia la propia condición: “* ...+ visión interior, llamados de otros tiempos, días. Visión de todo y de nada. Casi lo perfecto de un vacío asediado por la urgencia de lo desconocido. Tal vez así mismo debiese ser, porque su Excelencia viene de la luz de todas las glorias imaginables". A pesar de esto, debe oponerse al olvido: "Y sin embargo de todas sus glorias pasadas debe enfrentar el destierro, la impugnación de la baba, la pavorosa nada de un hastío sin espacio y sin tiempo que lo empuja hacia un viaje que no es de huida de lo concreto sino hijo del desengaño". En esta atmósfera de viaje mortuorio el narrador reitera: "Su

Excelencia ha decidido partir para siempre” (Cruz Kronfly, 1987: 10).

Atrás, "camino a la mar" de la muerte y el olvido, queda también el heroísmo, los hechos gloriosos y las hazañas de otros días. Y una extraña sensación no se deja esperar: “*...+ el vómito, vomitar. Expulsar los humores": señal del hastío frente a la propia existencia. De igual modo el navío, el medio para el viaje, se percibe del color de la ceniza, indicio de muerte: "Pues también la madera y los metales, como los días, conocen de su descenso al crepúsculo: un gris café azulado ocre ligeramente amarillo en los bordes y negro en la brea de la cubierta, cerca del puente" (Cruz Kronfly, 1987: 11).

Pero Bolívar no es el único en ser consciente de lo que le espera al final del río, también quienes lo acompañan saben del motivo que lo impulsó a decidir su partida: “-La fatalidad, mi general, eso es, la fatalidad”. Igualmente, la atmósfera habla desde el punto de partida acerca del destino final: "Huele a podredumbre de puerto, a restos descompuestos que el tiempo se encarga de lavar hasta poner en evidencia la niebla del hueso, de la espina, la nitidez de la almendra que viaja hacia su ser final una vez perfeccionado el despojo de la escoria" (Cruz Kronfly, 1987: 12).

A pesar de todo, el general “*...+ viste su mejor uniforme”, para dirigirse a la muerte cubierto de sus últimos vestigios de gloria, a fin de irse digno, sin dejarse apabullar por la derrota. Empero, “*...+ el uniforme también chorrea su alma, se destiñe. Durante toda la noche ha permanecido con él puesto, sin dormir"; es decir, aunque su gloria no le ha sido del todo arrebatada, sí se encuentra visiblemente opacada. Este personaje que va 
voluntariamente al olvido, sabe que "la promesa de alejarse para siempre debe cumplirse"; no obstante espera que sus conspiradores lo maten en cualquier momento, está paranoico. Despidiéndose de sus "últimos amigos", queda presa de un irreparable sentimiento de abandono. En medio de "grandes ruidos silenciosos en torno de todo y de nada" (Cruz Kronfly, 1987: 13), se percibe solo. Paradoja existencial: acompañado, pero solitario. La dignidad y poder del libertador van rumbo hacia el olvido. Lo que sobra es decadencia: Ahora su uniforme de gala es como de lienzos guardados en el naufragio de un cajón que se pierde en la hondura de los años *...+ y el uniforme que en la noche anterior brilló bajo las lámparas *...+ ahora parece bordado con sombras sobre lo que antes fueron hilos de oro y plata. En el pecho de su chaquetilla, brilla una medalla de oro. La última de las muchas que un día tuvo *...+ Arranca la medalla de su pecho y se la entrega: -Use usted, coronel, este recuerdo en mi nombre (Cruz Kronfly, 1987: 14).

La presencia del designio universal, la muerte, pesa sobre el alma: "El viaje es ahora un hecho que surge de la nada y cuya materia no es más que cada instante que pasa. Nadie habla, y el silencio es como una rara condensación de cualquier palabrerío inútil”. Bolívar no ignora que es -al decir de Heidegger-un ser-para-la-muerte, es consciente de ello: "Sabe que todo aquello es el comienzo del fin, y deja caer, contundente, toda su cabeza entre sus manos" (Cruz Kronfly, 1987: 14).

En medio de las ovaciones de la despedida, salta otro de los caracteres de la condición humana: el desprecio, el odio del otro. La gloria atribuida a Bolívar no es de consenso universal. No vivirá en la memoria como un héroe para todos: "Pero, de repente y como venido del centro del río donde el vapor acaba de desaparecer, se escucha un grito: - $i Q u e$ cesen los homenajes! - ¡No es un héroe el que se marcha sino un tirano despreciable!” (Cruz Kronfly, 1987: 15).

En el champán, metamorfoseado en vapor, el tiempo se vive como una ilusión: "Viven la ilusión de un tiempo muerto, estancado en aquel presente cuya transformación en pasado todos evitan". Y luego de la despedida, cada uno a lo suyo. Ninguno dejará de vivir por la partida del caudillo: "Cada quien decidió regresar a lo suyo, llevándose consigo hasta los más menudos sentimientos del día. Difícil pero sucedió”. En tal sentido, cada quien vive su propia historia, por más que la de uno sobresalga. Mientras Bolívar busca su lugar en la historia, los demás hacen lo propio: "Pues se trataba del retorno de cada quien, no a un 
lugar exacto sino a la bruma dentro de esa cosa espesa, imprevisible y traicionera que ellos conocían con el nombre de historia". La tristeza por la partida no dura para siempre. La vida sigue. ¡¿Qué creemos?!: “Horas más tarde, montados en sus caballos de piel de charco, murmuraron en coro con una contradanza de aquellas que ejecutaba impecable el Regimiento de las Milicias Pardas”(Cruz Kronfly, 1987: 16).

Todo lo anterior nos pone frente al teatro de una novela que reflexiona sobre la condición humana ante la conciencia de la muerte como límite de la existencia: ¡el comienzo del fin!

\section{Algunas ideas filosóficas de la novela}

\subsection{La estética de la muerte}

En Los motivos del arte y el tiempo (1986) Cruz Kronfly propone, a partir de una reflexión sobre lo que denomina una supuesta condición universal humana, que la cultura es un derivado del conflicto entre desaparecer y trascender ante la muerte, entre extinguirse y sobrevivir a ella: Si en un sentido casi ontológico, o sea en la perspectiva de una supuesta condición universal humana, el hecho inapelable de la muerte permitiera plantear como cierto que toda cultura deriva del conflicto entre desaparecer y trascender, extinguirse en medio de la ceniza definitiva o por el contrario sobrevivir gracias a la memoria que la imaginación y la cultura producen como cielo, historia, lienzo, escultura, museo, iglesia, lenguaje, familia, en fin (Cruz Kronfly, 1994: 165). A su vez, en La ceniza del libertador profundiza en el fenómeno de la muerte y de las formas de percibir las cosas cuando ésta se siente cerca, bajo el término estética de la muerte: El hombre del otro lado del enigma vuelve a depositar cristales de baba en el borde exterior de sus labios. Las babas se evaporan, las cicatrices brillan y dejan ver de pronto la estética de la muerte. Diminutos espejos se quiebran allí, donde la lengua trapea: *...+ La estética de la muerte ha dejado su baba en la transparente visión de las cosas. Y no habrá en adelante agua suficiente para lavar aquella baba, para expulsar de allí esa certeza desconcertante (Cruz Kronfly, 1987: 259).

Atendiendo a esto, se observa que la muerte trasciende el simple límite de la vida humana, aún más, la condiciona al crear toda una cultura, una visión del mundo. Así, la muerte se muestra como el enigma inicial de una teoría sobre la cultura y el arte, ya que el hombre, ante el hecho inminente de la muerte, busca la manera de trascender, de no desaparecer. 
Para ello, inventa el arte y la cultura como medios de sobrevivir a través de la imaginación y la memoria. Dicha estética de la muerte, más allá de considerar el hecho ineludible de la muerte en sí misma, abarca la representación que el hombre se hace de ella, que termina por configurar su forma de vivir: "La muerte, sí, la muerte, clave de toda cultura. Sin embargo, no la muerte en sí misma, sino las piadosas y hasta divertidas representaciones que de ellas nos hacemos" (Cruz Kronfly, 1994: 166). Tal representación ocurre debido a que el animal humano, al hacerse consciente de la muerte, crea unas imágenes que le fascinan y lo llenan de miedo y, a partir de tal conciencia, orienta su vida de acuerdo a las expectativas creadas por esas imágenes: el cielo, el infierno, la vida después de la muerte en un plano suprahumano, en fin, todas las utopías de eternidad aceptadas. De esta manera, la estética de la muerte funciona como una forma de representación que determina la que se hace sobre la vida: "como se piensa la muerte se piensa la vida" (Cruz Kronfly, 1994: 167).

En la novela, el general pregunta: “¿Cuánto tiempo tarda el agua que estamos viendo en mezclarse con el océano infinito?"; a lo que él mismo responde: "El mismo que el hombre, al morir, en mezclarse con la tierra de donde procede. Algunas partes se evaporan como la gloria humana” (Cruz Kronfly, 1987: 20). La estética de la muerte es, pues, una forma de percibir el viaje al último límite como evaporación de las obras humanas, ya que al final todo acaba. Parte de tal estética se relaciona con la sinestesia con que se asume ese trasegar hacia la muerte. En el caso del personaje que justifica la reflexión, es la náusea constante la que condiciona su forma de representársela:

-Quiero desocupar el estómago.

Palacios se detiene:

-¿Ya mismo?

-No, cuando llegue a la mar, siento que lo necesito.

-¿Y es que tiene usted náuseas?

-¿Náuseas yo?

-Bueno, malestar, digo.

-Olvídalo

(Cruz Kronfly, 1987: 21) 
Ir a la mar para vomitar no es otra cosa que acercarse a la inmensidad de la muerte con el fin de liberar su interior de tanto hastío; así, la muerte se representa como liberación de la pesadez de la existencia:

-No es comiendo sino vomitando como se arreglan ciertas cosas

-¿Qué cosas, señor?

-Estos entuertos que me empujan al destierro, que me tiran ceniza a la cara

-Si es así, ¿por qué entonces no lo hace de una vez?

-¿Qué?

-Echarlo todo afuera, ¿no lo dijo pues?

-Oh, sí, vomitar, lo haré en la mar, deja, lo haré en la mar, ya llegará el momento

(Cruz Kronfly, 1987: 21).

Antes del fin se agudizan los sentidos y se genera una manera particular de ver el mundo a través de la cercanía de la muerte: "No es el árbol, no son tampoco las aves. Es aquella especie de síntesis misteriosa, ese otro ser extraño que nace de la visión del conjunto" (Cruz Kronfly, 1987: 25). Ninguno puede percibir el delirio y el drama del interior humano como lo experimenta quien -paradójicamente- vive la muerte. Ninguno puede ver a quien sabe que morirá como él mismo se percibe: "Se trata de la visión de sí mismo, rostros alargados por el peso de las grandes incógnitas" (Cruz Kronfly, 1987: 53).

En el caso preciso del libertador, al manifestarse la estética de la muerte, esa baba que se queda en las cosas, su vida y sus logros empiezan a perder sentido para los demás. Cuando se acerca el fin, es evidente que aceptar la muerte que viene es distinto a que los otros la comprendan. De tal manera es juzgado por sus detractores: "La metamorfosis de este hombre no tiene comparación: de patriota sin tacha se ha convertido en un pobre ambicioso" (Cruz Kronfly, 1987: 264).

La estética de la muerte tiene su propia voz; su expresión es el delirio, que va y viene entre la memoria y olvido. Orgullosa habla a la conciencia y le muestra lo que queda luego del poder y la gloria: la inmensidad como el lugar del olvido. Lo único que queda por aspirar a encontrar es: un lugar para vomitar y morir. El infinito, la inmensidad. La estética de la muerte, con su voz delirante, se constituye en una profunda reflexión sobre lo efímero de la grandeza humana: Todo acaba, nada es para siempre. Las manifestaciones de la estética de 
la muerte a través de los sentidos muestran cómo, ante su inminencia, se juzga la obra de las propias manos: "Vuelve a mirar sus manos, toca uno a uno sus huesos evidentes, los cartílagos, el pellejo demasiado flojo. No cree en ellas, en aquello que ellas hicieron un día” (Cruz Kronfly, 1987: 316). De igual manera, se manifiesta como conversación consigo mismo: "Por los rincones oscuros, todavía no visitados por el alba que con tanta dificultad brilla en la ventana, brota la voz de la estética del que muere a solas respondiéndose él mismo sus propias dudas" (Cruz Kronfly, 1987: 340). Así, aunque "ningún día es el último", se acerca "el día" para Bolívar, del mismo modo que se aproxima el de cada quien. A éste le llega en el destierro, bajo la oscuridad de la ceniza, en medio de la más profunda miseria humana. No fue así como él lo quiso.

\section{$\underline{3.2 \text { El tiempo }}$}

Partiendo nuevamente de Los motivos del arte y el tiempo, Fernando Cruz Kronfly habla de tres dimensiones temporales: eternidad, posteridad y ahora. Al igual que la muerte, el tiempo (o los tiempos, para ser más preciso) son representaciones comunes a todas las etapas de la historia de la humanidad. Todos los hombres, al igual que todas las sociedades, se desgarran interiormente entre las demandas simultáneas de estos tres. Ahora bien, el tiempo no se define en sí mismo, sino en relación directa con la representación que se tenga de la muerte. Así, el papel de la muerte ante el tiempo consiste en definir el modo como se vive en lo público y lo privado, especialmente cuando se concibe la eternidad como conjuro de la muerte. Sin embargo, aunque la eternidad reprima o desplace el tiempo como porvenir y como ahora, no los desaparece. Mucho mejor, éstos siguen subsistiendo incluso como pruebas de esa eternidad improbable. En el caso de La ceniza del libertador, la expectativa de la fama y la gloria que reclama Bolívar continúa presente en el ahora como tiempo que busca prevalecer ante la eternidad de la muerte: "como si una dimensión del tiempo, lo eterno, sólo pudiera expresarse a través de otra: la historia” (Cruz Kronfly, 1994: 169).

De tal suerte, la eternidad se prueba a partir de la posteridad: el ser humano se representa lo eterno para sí como un reflejo que la imagen de la historia le guarda para el porvenir (v.g. la vida eterna del cristianismo: de acuerdo a como se les recuerde, como buenos o malos, piadosos o impíos, mansas ovejas o descarriados, los hombres van al cielo o al infierno). Esta es la angustia que aqueja al Bolívar-personaje de la novela: no qué le deparará la 
eternidad en la inmensidad de la muerte, sino cómo perdurará su memoria en los pueblos que libertó: "Mi gloria, mi gloria, ¿por qué la destruyen?” (Cruz Kronfly, 1987: 328).

La eternidad ha cedido a la secularización; es decir, el tiempo concreto de los hombres ya no debe sacrificarse por promesas eternas de un tiempo aparentemente superior desde lo ético. Se produce de esta manera un desplazamiento al mundo de un tiempo que siempre ha estado ahí, disfrazado de eterno, ante el cual no importaba renunciar al presente e irse contra la fama histórica. Por encima de éste, prevalece el tiempo histórico de la posteridad. Allí es el cuándo en el que Bolívar se debate: su preocupación es la gloria. En ese ahí es donde se desarrolla el drama de la novela. Para el libertador, sólo aparecen dos tiempos: la eternidad que pasó, su gloria y heroicidad y, la eternidad que viene, la muerte, el olvido. Estas dos muestran cómo los últimos vestigios de grandeza desaparecerán del recuerdo: Abajo, chorros de nubes pasan a sus pies. Dos eternidades me contemplan, piensa, la pasada y la que viene. Arriba, donde el veneno de la gloria se confunde con las pálidas hojas de la nieve, están sus juramentos, sus promesas. Corre, loca, la ceniza de los volcanes. Helada, como las manos de una mujer, palpa el rostro, huye, desaparece en el recuerdo (Cruz Kronfly, 1987: 56-57).

Cruz Kronfly señala que, a la vez que se secularizó lo sagrado, también se sacralizó lo profano. De esta forma, una representación profana como la patria toma un carácter sagrado en el proceso de conformación de la oligarquía burguesa. Vale la pena aquí recordar el mundo burocrático de la novela, en el que el lleno de requisitos en los documentos es condición sine qua non Bolívar puede acceder a su pasaporte, su libranza e incluso el envío del ultimátum para atracar el segundo piso del vapor. Los papeles, que son la patria y la tripulación del navío, se imponen por encima de la dignidad de su mismo fundador. En el fondo de la necesidad de trascendencia, que el hombre se propone ante la muerte y el fin definitivo, palpita la condición humana y sus respuestas ante el límite. La ceniza del libertador reflexiona y profundiza tal condición: la de un hombre ante la inmensidad de la muerte y su anhelo de trascender a la gloria. Por ello (y lo reitero) su preocupación: “Mi gloria, mi gloria, ¿por qué la destruyen?”.

\section{$\underline{3.3 \text { La condición humana }}$}

Uno de los referentes de Cruz Kronfly para introducirse en el proyecto de escribir una novela con profundidad filosófica, tomando como pretexto un personaje histórico, es la idea 
de condición humana sobre la que Kundera reflexiona: De esta manera el lector se olvida de su exigencia de datos precisos y meticulosos, porque sabe que el texto pretende y le propone de hecho más que eso, con miras a explorar lo que Kundera denominaba la condición humana. Y no porque el dato histórico no importe, sino porque la novela, aún siendo histórica, no le tiene como su objeto primordial, precisamente por ser novela (Cruz Kronfly, 1994: 194).

Consecuentemente, se hace necesario evocar las ideas del literato checo quien, pensando en la obra de Kafka, plantea su reflexión alrededor de las posibilidades de la novela en la exploración de los enigmas existenciales del ser humano, tema pertinente para esta lectura filosófica de La ceniza del libertador. Para Kundera, el poder se representa como laberinto sin fin. Las instituciones nada tienen que ver con los intereses humanos, ya que la vida del hombre no es más que una sombra y la realidad se encuentra en otra parte. En el mundo burocrático de La ceniza del libertador los documentos son la auténtica realidad, la existencia física es sólo un reflejo proyectado sobre la pantalla de las ilusiones. La patria no es más que papeles amarillentos que obstruyen las posibilidades humanas de un destierro digno, es decir, en el que al menos se cuente con un pasaporte para salir a otras latitudes y algo de dinero para sufragar los gastos del viaje. Lo paradójico es que al libertador, quien con largas y complejas campañas puso los cimientos de aquello que los engominados llaman patria, no se le permite ninguna de esas condiciones mínimas en nombre de ella misma: "De modo que, silenciadas las armas, los héroes se ven de pronto sin lenguaje, sin palabra concreta, pues en los salones de la patria los engominados, los sigilosos del orden sustituyen la verdad por la forma, la informalidad por los procedimientos pomposos, la naranja por la cáscara” (Cruz Kronfly, 1994: 194).

Una de las cuestiones más absurdas del hombre actual es el castigo, ya que ante éste las justificaciones de parte de quienes lo infligen no son del todo claras, por lo cual son los sufrientes quienes buscan su justificación. Se tiene así a Bolívar preguntando desesperadamente por la razón de su oprobio: ¡mi gloria, mi gloria, ¿por qué la destruyen?! Este carácter disparatado del castigo le abre la puerta a lo cómico, que se observa desde el interior de la situación humana. La caricatura del Bolívar que putea, patea, tira flatulencias, defeca con cierto aire de alegría y orgullo, gargajea su pañuelo y lo lleva al bolsillo, etc., puede despertar en el lector una leve sonrisa. Sin embargo, desde estas acciones risibles se 
muestra su dimensión trágica, ya que son manifestaciones de su proximidad al fin. La condición humana actual, vivamente representada y profundizada a través de la novela, evidencia el proceso de burocratización de la actividad social que transforma todas las instituciones en laberintos sin fin, despersonalizando al individuo. Así es como nace la patria. Bolívar se ve obligado a llenar todos los requisitos formales aún para solicitar una entrevista con el capitán del vapor. En ese mundo burocrático solamente hay órdenes y reglas. Es el mundo de la obediencia, lo mecánico y lo abstracto. Lo burocrático se impone así como posibilidad humana, forma elemental de ser. Bolívar espera su pasaporte, su libranza, su solicitud de ver al capitán, la respuesta al ultimátum para asaltar el segundo piso (que es rechazada por no cumplir con todos los requerimientos). Así, la burocracia de los papeles dilata la agonía de su viaje presente al futuro de la muerte.

Respecto a las situaciones humanas, Kundera señala "Toda situación es obra del hombre y no puede contener más que lo que está en él: podemos, por lo tanto, imaginar que existe (ella y toda su metafísica) desde hace mucho tiempo en tanto que posibilidad humana" (Kundera, 1986: 132). Atendiendo a esto, puede observarse todo lo que rodea el viaje de Bolívar hacia la mar de la muerte y el olvido, en medio del fracaso, como una situación humana, plenamente posible para todos los hombres. En ese sentido, se puede arriesgar la afirmación de que Bolívar sea un prototipo del Hombre: de aquel que sufre su posibilidad humana y que, por tanto, puede ser la imagen de todos nosotros. Una bien fundada predicción del destino de los lectores.

La historia sobre los últimos días de Bolívar muestra al hombre que está detrás, en la encrucijada entre el poder y la miseria, la gloria y el olvido. Es el descubrimiento de una posibilidad de aquello que se está por descubrir: la condición humana: "En las situaciones inéditas, desvela lo que es el hombre, lo que está en él "desde hace mucho tiempo", lo que son sus posibilidades" (Kundera, 1986: 132). Este pensar la novela lleva a Kundera a concluir que ésta ahonda en la condición humana mejor de lo que ninguna elucubración metafísica puede hacerlo. Característica plenamente aplicable a La ceniza del libertador: Si estimo tanto y tan apasionadamente la herencia de Kafka, si la defiendo como si de mi herencia personal se tratara, no es porque crea útil imitar lo inimitable (y descubrir una vez más lo kafkiano), sino por ese formidable ejemplo de autonomía radical de la novela (de la poesía que es novela). Gracias a ella Franz Kafka dijo sobre nuestra condición humana (tal 
como se manifiesta en nuestro siglo) lo que ninguna reflexión sociológica o politológica podrá decirnos (Kundera, 1986: 133).

\section{Bibliografía}

Cruz Kronfly, Fernando La ceniza del libertador. Bogotá: Planeta. (1987).

Cruz Kronfly, Fernando La ceniza del libertador. Manizales: Editorial Universidad de Caldas. (2008).

Kundera, Milan El arte de la novela. Barcelona: Tusquets. (1986). 